\title{
Extrapulmonary Features of COVID-19: A Concise Review
}

\author{
Sachin A Adukia ${ }^{1}$, Radhika S Ruhatiya ${ }^{2}$, Harish M Maheshwarappa ${ }^{3}$, Ramya B Manjunath ${ }^{4}$, Gagan N Jain ${ }^{5}$
}

\begin{abstract}
Typical manifestations of coronavirus disease (COVID-19) involve the upper and lower respiratory tract. But as the pandemic surges, we are encountering numerous case reports and series of extrapulmonary presentations of COVID-19 in the outpatient department. Abundant retrospective data have also cited various extrapulmonary complications in the hospitalized COVID-19 patients. This knowledge needs to be condensed and disseminated in order to improve COVID-19 surveillance and to reduce the accidental exposure of healthcare workers. Our review suggests that gastrointestinal tract, cardiovascular system, nervous system, renal system, and manifestations due to hematological abnormalities are common masqueraders to watch out for.
\end{abstract}

Keywords: Asymptomatic, Atypical, COVID-19, Pulmonary embolism.

Indian Journal of Critical Care Medicine (2020): 10.5005/jp-journals-10071-23476

\section{INTRODUCTION}

The ongoing pandemic of coronavirus disease (COVID-19) leads to a typical presentation of respiratory features due to the affinity of the novel coronavirus (SARS-CoV-2) for the upper and lower respiratory tracts. But increasingly, the recent literature has shown varied systemic involvement. Extrapulmonary sites are being recognized as sites of disease expression and virus transmission. ${ }^{1}$ These include the gastrointestinal tract (GIT), nervous system, cardiovascular system (CVS), renal system, eyes, and manifestations due to hematological abnormalities.

\section{Materials and Methods}

\section{Inclusion and Exclusion Criteria}

All retrospective clinical studies, case series, and case reports with data on extrapulmonary manifestations in COVID-19 that were published from the end of December 2019 till the end of April 2020 were included. Studies that did not mention extrapulmonary manifestations were excluded.

\section{Literature Search}

The review was based on publications available on PubMed and data collected by the WHO. Search terms we used were "2019-nCoV," "SARS-CoV-2," or "COVID-19" combined with "asymptomatic," "gastrointestinal," "cardiac," "neurological," "hepatic," "hematological," "ophthalmological," "dermatological," "psychiatric," "hematological," "renal," and "atypical."

\section{Data Extraction}

We reviewed eligible studies and extracted data like country of origin, study period, demographics, systemic manifestations, and the incidence of symptoms. Two researchers, SAA and RSR, extracted the data by consensus; major disagreements were settled by the senior researcher, HM.

A case vignette at the outset will drive home the purpose of this review. A 42-year-old male was referred by his primary physician to the emergency department with a history of 8 days of testicular pain migrating into the abdomen, back, and chest. Although he had a fever 2 days back, he denied respiratory symptoms. Clinical examination revealed diffuse abdominal tenderness. Computerized
${ }^{1}$ Department of Neurology, NH Health City, Bengaluru, Karnataka, India

2,3 Department of Critical Care Medicine, Mazumdar Shaw Medical Centre, Narayana Hrudayalaya, Bengaluru, Karnataka, India

${ }^{4}$ Department of Anesthesia, NH Health City, Bengaluru, Karnataka, India

${ }^{5}$ Hemraj Jain Hospital, New Delhi, India

Corresponding Author: Harish M Maheshwarappa, Department of Critical Care Medicine, Mazumdar Shaw Medical Centre, Narayana Hrudayalaya, Bengaluru, Karnataka, India, Phone: +918067506870, e-mail: dr.harishmm@rocketmail.com

How to cite this article: Adukia SA, Ruhatiya RS, Maheshwarappa HM, Manjunath RB, Jain GN. Extrapulmonary Features of COVID-19: A Concise Review. Indian J Crit Care Med 2020;24(7):575-580.

Source of support: Nil

Conflict of interest: None

tomography (CT) of the abdomen captured the lung bases. Pulmonary ground-glass opacification and consolidation consistent with pneumonia and possible colitis were noted. Two days into hospitalization, his primary physician notified his COVID-19-positive status. He had attended a biotechnology conference 2 weeks prior in a COVID-19-impacted area. Eventually, many healthcare workers (HCWs) had accidental exposure to SARS-CoV-2. ${ }^{2}$

\section{Asymptomatic Patient}

Individuals with positive reverse transcription-polymerase chain reaction (RT-PCR) results, who never develop any signs or clinically symptoms of COVID-19, are considered as asymptomatic. Those with positive RT-PCR results, who have no signs or symptoms of COVID-19 at testing but eventually develop symptoms, are considered as presymptomatic. About $80 \%$ COVID-19 cases in China are asymptomatic. ${ }^{3}$ The possible mechanism is that the nasal epithelial cells shelter genes for innate immunity and the viral entry-associated genes. An adequate early immune response can limit viral replication and prevent its spread into the lungs. Thus, the patient would have no or mild symptoms. ${ }^{4}$ The relative transmissibility of such cases is significantly smaller than 
Table 1: Cardiac manifestations of COVID-19

\begin{tabular}{ll}
\hline Cardiac manifestation & Frequency reported \\
\hline Coronary artery disease & $4.2-25 \% \%^{7,8}$ \\
Acute cardiac injury: & $7.2 \%{ }^{7}$ \\
$\quad$ Myocardial infarction-type 2 & \\
$\quad$ Myocarditis & \\
Arrhythmia: Atrial arrhythmias are & $16.7 \%{ }^{7}$ \\
more common & \\
Cardiogenic shock & $8.7 \%^{7}$ \\
Heart failure & $49 \%{ }^{8}$ \\
Cardiac tamponade & Case report $^{9}$ \\
Myopericarditis & Case report $^{10}$ \\
\hline
\end{tabular}

symptomatic ones. ${ }^{5}$ Evidence stating otherwise is also published. ${ }^{6}$ This needs further appraisal.

\section{Cardiovascular System}

Cardiac manifestations of COVID-19 (Table 1) commonly include acute cardiac injury, shock, and arrhythmia in $7.2,8.7$, and $16.7 \%$, respectively. Intensive care unit (ICU) patients have a higher prevalence of CVS involvement. ${ }^{7}$

Myocardial injury among hospitalized COVID-19 patients ranges from 7 to $28 \%{ }^{11,12}$ Usually, even COVID-19 patients with myocardial injury present with the typical symptoms and signs of SARS-CoV-2 infection. A minority may present with cardiac symptoms such as chest pain, palpitations, ${ }^{13}$ or fatigue. Evidence of myocardial injury like increased cardiac troponin or ECG abnormalities can be seen in $20 \% .^{11} \mathrm{~A}$ direct relation between the magnitude of troponin elevation and mortality has been reported. ${ }^{7,11,12} \mathrm{~A}$ few others may present as an acute coronary syndrome (ACS). In such cases, the myocardial infarctions are type 2 (consequent to a mismatch between oxygen supply and demand). Putative causes for this mismatch include direct myocardial injury from hemodynamic derangement, hypoxemia, inflammatory myocarditis, stress cardiomyopathy, microvascular dysfunction or thrombosis due to hypercoagulability, or systemic inflammation with cytokine storm syndrome (CSS), which may also destabilize coronary artery plaques. ${ }^{14}$ Some patients develop systemic hyperinflammatory response with vasodilatory shock. Concomitant myocardial suppression and cardiogenic shock may ensue. ${ }^{15}$

Clinical manifestations of acute coronary artery disease (CAD) in COVID-19 are similar to those without the virus. Concurrent respiratory symptoms may or may not accompany cardiac symptoms. ${ }^{16,17}$ Prevalence of CAD in COVID-19 ranges from 4.2 to $25 \%{ }^{7,8}$ Coronary artery disease is commoner in critically ill or deceased patients. ${ }^{8}$

Arrhythmias in COVID-19 may remain asymptomatic or may be overshadowed by typical respiratory manifestations. However, palpitations can be presenting symptom in $7.3 \% .{ }^{13,18}$ But more frequently, arrhythmias are an additional feature in patients presenting with conditions that may predispose to the development of arrhythmias. Examples include myocardial injury, myocardial ischemia, hypoxia, shock (septic or cardiogenic), or electrolyte disturbances like hypokalemia. ${ }^{19}$ Further, atrial arrhythmias are more common among patients requiring mechanical ventilation. ${ }^{20}$

In a retrospective study, heart failure has been identified as a complication in $49 \%$ of the deceased. ${ }^{8}$ Heart failure may be precipitated by acute illness in preexisting known or undiagnosed heart disease (CAD, hypertensive heart disease), or by acute myocardial injury (e.g., acute myocardial infarction, stress cardiomyopathy, CSS). A case of COVID-19-associated cardiac tamponade in a middle-aged female has been reported. ${ }^{9}$ Similarly, COVID-19 presenting as myopericarditis in a middle-aged female without respiratory symptoms has been reported. ${ }^{10}$ Outcomes of these cases were not mentioned.

Cardiac pathology in COVID-19 may occur through multiple mechanisms. Oudit et al. in 2009 detected viral RNA in 35\% of autopsied human heart samples from severe acute respiratory distress syndrome patients. This suggested that viral infection directly causes damage to cardiomyocyte. ${ }^{21}$ Angiotensin converting enzyme-2 (ACE2) receptor expression in the CVS may possibly augment viral effects on the myocardial tissue. ${ }^{22}$ But, SARS-CoV-2 is not a known cardiotropic virus such that it may cause viral myocarditis. The relationship between COVID-19 and myocardial injury is yet to be characterized. Second, hypoxemia due to COVID-19 pneumonia leads to anaerobic respiration, intracellular acidosis, and influx of calcium. Subsequently, there is apoptosis of cardiomyocytes. Third, patients in ICU have higher concentrations of inflammatory factors like monocyte chemoattractant protein1 , interleukin-1 $\beta$, interferon- $\gamma$, and interferon inducible protein10. These could accentuate the CSS. ${ }^{23}$ The prognosis for COVID-19 patients is worse with CVS comorbidities, with mortality approaching $>10 \% .^{24}$

\section{Neuromuscular System}

Neurological manifestations (Table 2) in COVID-19 can be categorized into three categories: central nervous system (CNS), peripheral nervous system (PNS), and skeletal muscle injury. ${ }^{25}$

Overall, neurological manifestations have been recorded in $36.4 \%$ cases. Neurologic manifestations tend to occur early in the illness (median time, 1-2 days). Some patients have presented only with neurologic manifestations and no typical symptoms. Neurologic manifestations are more likely to develop in severe COVID-19 cases ( $45.5 \%$ vs $30 \%)$. SARS-CoV-2 probably enters the CNS through the hematogenous or retrograde neuronal route. The expression and distribution of the ACE2 receptor in the CNS and skeletal muscle tissue might explain the virus's affinity and resultant neurologic manifestations. ${ }^{25}$

The presence of SARS-CoV-2 has been confirmed in the cerebrospinal fluid of COVID-19 patients by genome sequencing. ${ }^{28}$ This is definitive evidence of SARS-CoV-2 causing viral encephalitis. Toxic encephalopathy can also occur in patients with COVID-19 as they tend to have severe hypoxia and viremia. ${ }^{31}$ The multiple drugs in the ICU also are potential culprits. SARS-CoV-2 can cause CSS leading to acute cerebrovascular disease. ${ }^{32,33}$ In addition, elevated levels of D-dimer and thrombocytopenia in critically ill COVID-19 patients increase the occurrence of acute cerebrovascular events. ${ }^{34}$ Also, SARS-CoV-2 binds to ECA2 receptors on endothelial cells. This can lead to an increase in blood pressure, which together with thrombocytopenia and coagulation disorders can increase the risk of ischemic and hemorrhagic strokes. ${ }^{25,35}$

A unique feature of the COVID-19 disease can be the absence of dyspnea, which is "an unpleasant urge to breathe." Even the most severe cases presenting with tachypnea and tachycardia may not complain of dyspnea. In a Wuhan cohort, nearly half of those who were intubated or dead did not present dyspnea. ${ }^{26,27}$ Cytokine storm syndrome in COVID-19 could damage the C-pulmonary fibers and cause a total or partial loss of their function. ${ }^{36}$ 
Table 2: Neuromuscular manifestations of COVID-19

\begin{tabular}{|c|c|c|}
\hline Part of neuraxis & Manifestation & Frequency reported \\
\hline \multirow{6}{*}{$\begin{array}{l}\text { Central nervous system } \\
\text { manifestations }(25 \%)\end{array}$} & - Dizziness & $17 \%^{25}$ \\
\hline & - Headache & $13 \%{ }^{25}$ \\
\hline & $\begin{array}{l}\text { - Impaired consciousness-confusion, delirium, } \\
\text { somnolence, stupor, coma }\end{array}$ & $16 \%{ }^{25}$ \\
\hline & $\begin{array}{l}\text { - Acute cerebrovascular disease-acute ischemic stroke, } \\
\text { intracranial hemorrhage }\end{array}$ & $3 \%{ }^{25}$ \\
\hline & - Ataxia & $1 \%{ }^{25}$ \\
\hline & - Seizure & $1 \%^{25}$ \\
\hline \multirow{4}{*}{$\begin{array}{l}\text { Peripheral nervous system } \\
\text { manifestations ( } 9 \%)\end{array}$} & - Taste impairment & $5.6 \%{ }^{25}$ \\
\hline & - Smell impairment & $5 \%^{25}$ \\
\hline & - Vision impairment & $1.4 \%{ }^{25}$ \\
\hline & - Nerve pain & $2.3 \%{ }^{25}$ \\
\hline \multirow{2}{*}{$\begin{array}{l}\text { Skeletal muscle injury } \\
\text { manifestations (11\%) }\end{array}$} & - Myalgia & Up to $11 \%$ cases have \\
\hline & - Elevated creatine kinase level $>200 \mathrm{U} / \mathrm{L}$ & muscle injury $^{25}$ \\
\hline \multirow[t]{4}{*}{ Unusual manifestations } & - Absence of dyspnea & $46-62 \%^{26,27}$ \\
\hline & - Viral encephalitis & Case report ${ }^{28}$ \\
\hline & - Acute hemorrhagic necrotizing encephalopathy & Case report ${ }^{29}$ \\
\hline & - Guillain-Barre syndrome & Case report ${ }^{30}$ \\
\hline
\end{tabular}

Many COVID-19 patients report sudden loss of smell or taste even in the absence of nasal symptoms. ${ }^{37}$ Analysis of a European multicenter case registry has found that 85.6 and $88 \%$ of patients describe disorders of smell and taste, respectively. Of these, olfactory dysfunction is the initial symptom in $12 \%$. $^{38}$

Magnetic resonance imaging (MRI) of the brain of a COVID19 patient presenting with fever and altered sensorium showed contrast-enhancing, multifocal, symmetrical hemorrhagic lesions in both thalamus, insula, and medial temporal lobes. He was diagnosed as having acute hemorrhagic necrotizing encephalopathy, ${ }^{29}$ probably due to CSS of COVID-19. ${ }^{32}$

An elderly male was diagnosed as Guillain-Barre syndrome, and 1 week later, he had symptoms of COVID-19 with fever and dry cough. However, this relation is likely to be coincidental. ${ }^{30}$

\section{Gastrointestinal System}

The overall incidence of gastrointestinal symptoms (Table 3) of COVID-19 varies from 3 to $70 \% .{ }^{46}$ SARS-CoV-2 may probably cause acute gastritis and enteritis, leading to vomiting, nausea, and diarrhea. ${ }^{47}$ Some of the COVID-19 cases may present with digestive manifestations without any respiratory symptoms or fever. This results in unexpected exposure to the $\mathrm{HCWs}^{45}$

Literature reported from China has suggested that approximately 50\% COVID-19 patients will have at least one gastrointestinal symptom. ${ }^{40,41}$ As a corollary, those with gastrointestinal symptoms are associated with a $70 \%$ increased risk of testing COVID-19 positive. ${ }^{48}$ High expression of ACE2 in esophageal epithelial cells and the absorptive enterocytes from ileum and colon is known. ${ }^{49}$

COVID-19 patients with GIT symptoms suffer a severe or critical illnesses such as ARDS, liver injury, and shock more frequently than in those without $(22.97 \%$ vs $8.14 \%) .{ }^{47}$ Fang et al. have reported that $85 \%$ of critical cases have digestive symptoms and $45 \%$ of these have diarrhea. ${ }^{50}$ However, conflicting data have also been published. It states that among COVID-19 patients with GIT symptoms there is a nonsignificant trend toward a lower rate of ICU admission, and a significantly lower rate of death $(0.0 \%$ with gastrointestinal symptoms vs $5.0 \%$ without) during short-term follow-up.
Table 3: Gastrointestinal manifestations of COVID-19

\begin{tabular}{ll}
\hline Digestive manifestation & Frequency reported \\
\hline Anorexia & $30-40 \%^{39,40}$ \\
Diarrhea & $2-50 \%^{41}$ \\
Nausea/vomiting & $2-12 \%^{26,39,40}$ \\
Abdominal pain & $2-4 \%^{39,40}$ \\
Digestive symptoms only & $3-23 \%^{39,40}$ \\
Abnormal liver tests: & \\
$\quad$ Aminotransferases & $14-53 \%^{26,42}$ \\
$\quad$ Bilirubin & $10-18 \%$ \\
Virus detected in stool & $50-55 \%^{39,43,44}$ \\
Uncommon symptoms & Gastrointestinal bleeding \\
\hline
\end{tabular}

These might indicate an indolent form of COVID-19 in those with gastrointestinal symptoms. ${ }^{48}$ Gastrointestinal symptoms in COVID19 patients are more frequent in the presence of preexisting chronic liver disease ( $10.81 \%$ vs $2.95 \%$ in those without). ${ }^{47}$

\section{Renal Manifestations}

Studies from China has reported AKI in 25-29\% critically ill patients of COVID-19 or the deceased. ${ }^{8,51}$ Renal abnormalities such as massive albuminuria on the 1st day of admission in $34 \%$ have been reported, while proteinuria developed in $63 \%$ of all cases during hospitalization. ${ }^{52}$ Another study on hospitalized COVID-19 patients has reported proteinuria and hematuria in $44 \%$ and hematuria on admission in $26.7 \% .{ }^{53}$ Blood urea nitrogen can be elevated in $27 \%$ COVID-19 patients, and in $66 \%$ of those who have died..$^{52}$ Kidneys show reduced density on CT scan, suggestive of inflammation and edema. COVID-19 patients with both chronic kidney disease (CKD) and hypertension are at risk for more severe disease (3.3 vs $0.4 \%){ }^{54,55}$ Postulated mechanisms of kidney injury include CSS or direct cellular injury by the virus. Recently, SARS-CoV-2 has been isolated from the urine sample of an infected patient, suggesting the kidney as the target due to the expression of the ACE2 receptor on renal tubular cells. ${ }^{56}$ 


\section{Ocular Manifestations}

Ocular involvement in COVID-19 is uncommon with prevalence between $0.9^{26}$ and $31 \% .{ }^{57}$ The patient may even present with an ocular manifestation. Symptoms include watery eyes, which can be a presenting feature, followed by increased secretions, chemosis, ocular irritation, and foreign body sensation. Examination findings include unilateral or bilateral bulbar conjunctiva injection, follicular reaction of the palpebral conjunctiva, epiphora, and mild eyelid edema. These suggest follicular conjunctivitis. Unusual reports of presentation as conjunctivitis or keratoconjunctivitis ${ }^{58}$ have been published. It generally carries a good prognosis. Positive RT-PCR results of a conjunctival swab, as well as nasopharyngeal swabs, have been obtained in two patients. ${ }^{57}$ Possible pathogenetic mechanisms include direct inoculation of the ocular tissues from respiratory droplets or aerosolized viral particles, migration from the nasopharynx via the nasolacrimal duct, or hematogenous spread through the lacrimal gland. ${ }^{59}$

\section{Hematological Abnormalities}

COVID-19 may herald a hypercoagulable state with an increased risk of venous thromboembolism (VTE) called thromboinflammation. ${ }^{60}$ Common VTE events include pulmonary embolism (PE), deep vein thrombosis, and catheter-associated thrombosis. The rate of these events in critically ill COVID-19 patients is 33\%, PE being the commonest (vs $3 \%$ in the non-ICU setting). ${ }^{61}$ Venous thromboembolism occurs despite using prophylactic-dose anticoagulation. $^{62}$ Exact incidence of acute PE in COVID-19 is not clear, but it may be as high as $20 \% .{ }^{63}$ Pathogenesis of PE involves the elevated D-dimer level and thromboinflammation. ${ }^{34,60,64}$ Obesity also contributes to increased PE frequency. ${ }^{65}$ Arterial events such as myocardial infarction, ischemic strokes, and peripheral arterial thromboembolism have been reported. Microvascular thrombosis may affect the lungs ${ }^{60,66}$ due to hypercoagulability, direct endothelial injury, complement activation, or other processes.

Thrombocytopenia in COVID-19 is well known, while the underlying mechanisms are not. It is associated with an increased risk of severe illness and mortality in COVID-19 patients. ${ }^{67}$ However, symptomatic thrombocytopenia is uncommon. On the contrary, in COVID-19, thrombosis is common. Bleeding in the form of intracranial hemorrhage has been outlined above.

Antiphospholipid antibodies can also arise transiently in patients with critical illness ${ }^{68}$ and rarely lead to multifocal thrombosis in critical patients. Cases of APLA syndrome in critically ill cases of COVID-19 have also been reported. ${ }^{69}$

\section{Psychiatric Manifestations}

Regardless of disease exposure, during an outbreak individuals with preexisting mental illnesses may experience anxiety, depression, panic attacks, somatic symptoms, posttraumatic stress disorder, delirium, psychosis, and even suicidality. ${ }^{70}$ Healthcare workers face a lack of social support and communication, maladaptive coping, and lack of training. They can experience psychiatric morbidities due to these factors. ${ }^{71}$

\section{Dermatological Manifestations}

Cutaneous manifestations have been reported in around $20 \%$ COVID-19 patients. ${ }^{72}$ Another review noted that cutaneous manifestations were the presenting features in $12.5 \%$. Common manifestations in decreasing frequency are maculopapular exanthem (morbilliform), papulovesicular rash, urticaria, painful acral red-purple papules, livedo reticularis lesions, and petechiae. Lesions are commoner on the trunk than extremities $(66.7 \%$ vs $19.4 \%$ ). Lesions tend to heal spontaneously in 10 days. ${ }^{73} \mathrm{~A}$ hypothesis states that cutaneous blood vessels contain viral particles. Blood immune complexes can activate cytokines and cause lymphocytic vasculitis. This can result in vasodilatation and spongiosis. $^{74}$

\section{Unusual Presentations}

All the cases below had an atypical presentation; they were diagnosed as COVID-19 by RT-PCR. The CT chest was done wherever necessary. A middle-aged female with arthralgia with fever and thrombocytopenia subsequently developed pneumonia and diagnosed as COVID-19. ${ }^{75}$ An elderly female presented with syncope and orthostatic hypotension, and 2 days later with altered sensorium. Eventually, COVID-19 was confirmed. ${ }^{76}$ A COVID-19 patient presented after 12 days of discharge with hemoptysis, dyspnea, and worsening chest pain due to segmental PE with no risk factor for VTE. ${ }^{77}$ A middle-aged female presented with dark-colored urine, followed by mild fever, and liver function derangement favoring acute hepatitis. This was an acute, nonicteric hepatitis presentation of COVID-19. ${ }^{78}$ A hospitalized case of COVID19 with respiratory distress developed acute liver failure alongside multiorgan failure. ${ }^{79}$

\section{Limitations of Study}

Knowledge about the COVID-19 pandemic is evolving. We included data only up to April 30, 2020. By the time this write-up is published, newer data might become available. Second, we reviewed case reports, case series, retrospective studies, and registries. All of these tend to be inherently biased.

\section{Conclusion}

Up-to-date knowledge of atypical and extrapulmonary manifestations can help to increase surveillance of COVID-19 and can protect the HCWs. A high index of suspicion for COVID19 is required when tackling patients with extrapulmonary manifestations. Notable manifestations among them are gastrointestinal-anorexia, diarrhea; cardiovascular-arrhythmias, myocarditis; consequences of hypercoagulability_pulmonary embolism, ACS, ischemia stroke.

\section{References}

1. Hamming I, Timens W, Bulthuis ML, Lely AT, Navis G, van Goor H. Tissue distribution of ACE2 protein, the functional receptor for SARS coronavirus. A first step in understanding SARS pathogenesis. J Pathol 2004;203(2):631-637. DOI: 10.1002/path.1570. PMID: 15141377; PMCID: PMC7167720.

2. Kim J, Thomsen T, Sell N, Goldsmith AJ. Abdominal and testicular pain: an atypical presentation of COVID-19. Am J Emerg Med 2020;38(7):1542.e1-1542.e3. DOI: 10.1016/j.ajem.2020.03.052.

3. World Health Organization, Report of the WHO-China Joint Mission on coronavirus disease 2019 (COVID-19). 2020. https://www.who. int/docs/default-source/coronaviruse/who-chinajoint-mission-oncovid-19-final-report.pdf.

4. Sungnak W, Huang N, Bécavin C, Berg M, Queen R, Litvinukova M, et al. SARS-CoV-2 entry factors are highly expressed in nasal epithelial cells together with innate immune genes. Nat Med 2020(5):1-7. DOI: 10.1038/s41591-020-0868-6. 
5. He D, Zhao S, Lin Q, Zhuang Z, Cao P, Wang MH, et al. The relative transmissibility of asymptomatic cases among close contacts. Int J Infect Dis 2020. DOI: 10.1016/j.ijid.2020.04.034.

6. Yin G, Jin H. Comparison of transmissibility of coronavirus between symptomatic and asymptomatic patients: Reanalysis of the Ningbo COVID-19 data. JMIR Public Health Surveill 2020;6(2):e19464. DOI: $10.2196 / 19464$

7. Wang D, Hu B, Hu C, Zhu F, Liu X, Zhang J, et al. Clinical characteristics of 138 hospitalized patients with 2019 novel coronavirus-infected pneumonia in Wuhan, China. JAMA 2020;323(11):1061-1069. DOI: 10.1001/jama.2020.1585.

8. Chen T, Wu D, Chen H, Yan W, Yang D, Chen G, et al. Clinical characteristics of 113 deceased patients with coronavirus disease 2019: retrospective study. BMJ 2020. 368. DOI: 10.1136/bmj.m1091.

9. Hua A, O'Gallagher K, Sado D, Byrne J. Life-threatening cardiac tamponade complicating myo-pericarditis in COVID-19. Eur Heart J 2020;41(22):2130. DOI: 10.1093/eurheartj/ehaa253.

10. Inciardi RM, Lupi L, Zaccone G, Italia L, Raffo M, Tomasoni $D$, et al. Cardiac involvement in a patient with coronavirus disease 2019 (COVID-19). JAMA cardiology 2020. DOI: 10.1001/ jamacardio.2020.1096.

11. Shi S, Qin M, Shen B, Cai Y, Liu T, Yang F, et al. Association of cardiac injury with mortality in hospitalized patients with COVID-19 in Wuhan, China. JAMA cardiology 2020. DOI: 10.1001/jamacardio.2020.0950.

12. Lippi G, Lavie CJ, Sanchis-Gomar F. Cardiac troponin I in patients with coronavirus disease 2019 (COVID-19): Evidence from a meta-analysis. Prog Cardiovasc Dis 2020. DOI: 10.1016/j.pcad.2020.03.001.

13. Liu K, Fang YY, Deng Y, Liu W, Wang MF, Ma JP, et al. Clinical characteristics of novel coronavirus cases in tertiary hospitals in Hubei Province. Chin Med J (Engl) 2020;133(9):1025-1031. DOI: 10.1097/ CM9.0000000000000744.

14. Libby P, Loscalzo J, Ridker PM, Farkouh ME, Hsue PY, Fuster V, et al. Inflammation, immunity, and infection in atherothrombosis: JACC review topic of the week. J Am Coll Cardiol 2018;72(17):2071-2081. DOI: 10.1016/j.jacc.2018.08.1043.

15. Siddiqi HK, Mehra MR. COVID-19 illness in native and immunosuppressed states: A clinical-therapeutic staging proposal. J Heart Lung Transplant 2020;39(5):405-407. DOI: 10.1016/j. healun.2020.03.012.

16. Zheng YY, Ma YT, Zhang JY, Xie X. COVID-19 and the cardiovascular system. Nature Reviews Cardiology 2020;17(5):259-260. DOI: 10.1038/ s41569-020-0360-5.

17. Dong N, Cai J, Zhou Y, Liu J, Li F. End-stage heart failure with COVID19: strong evidence of myocardial injury by 2019-nCoV. JACC: Heart Failure 2020;8(6):515-517. DOI: 10.1016/j.jchf.2020.04.001.

18. Driggin E, Madhavan MV, Bikdeli B, Chuich T, Laracy J, Biondi-Zoccai G, et al. Cardiovascular considerations for patients, health care workers, and health systems during the COVID-19 pandemic. J Am Coll Cardiol 2020;75(18):2352-2371. DOI: 10.1016/j.jacc.2020.03.031.

19. Lazzerini PE, Boutjdir M, Capecchi PL. COVID-19, arrhythmic risk and inflammation: mind the gap!. Circulation 2020(1). DOI: 10.1161/ CIRCULATIONAHA.120.047293.

20. Goyal P, Choi JJ, Pinheiro LC, Schenck EJ, Chen R, Jabri A, et al. Clinical characteristics of COVID-19 in New York city. N Engl J Med 2020;382(24):2372-2374. DOI: 10.1056/NEJMc2010419.

21. Oudit GY, Kassiri Z, Jiang C, Liu PP, Poutanen SM, Penninger JM, et al. SARS-coronavirus modulation of myocardial ACE2 expression and inflammation in patients with SARS. Eur J Clin Invest 2009;39(7):618625. DOI: $10.1111 /$ j.1365-2362.2009.02153.x.

22. Lu R, Zhao X, Li J, Niu P, Yang B, Wu H, et al. Genomic characterisation and epidemiology of 2019 novel coronavirus: Implications for virus origins and receptor binding. The Lancet 2020;395(10224):565-574. DOI: 10.1016/S0140-6736(20)30251-8.

23. Huang C, Wang Y, Li X, Ren L, Zhao J, Hu Y, et al. Clinical features of patients infected with 2019 novel coronavirus in Wuhan, China. The Lancet 2020;395(10223):497-506. DOI: 10.1016/S0140-6736(20)30183-5.

24. Chen N, Zhou M, Dong X, Qu J, Gong F, Han Y, et al. Epidemiological and clinical characteristics of 99 cases of 2019 novel coronavirus pneumonia in Wuhan, China: a descriptive study. The Lancet 2020;395(10223):507-513. DOI: 10.1016/S0140-6736(20)30211-7.

25. Mao L, Jin H, Wang M, Hu Y, Chen S, He Q, et al. Neurologic manifestations of hospitalized patients with coronavirus disease 2019 in Wuhan, China. JAMA neurology 2020;77(6):1-9. DOI: 10.1001/ jamaneurol.2020.1127.

26. Guan WJ, Ni ZY, Hu Y, Liang WH, Ou CQ, He JX, et al. Clinical characteristics of coronavirus disease 2019 in China. N Engl J Med 2020;382(18):1708-1720. DOI: 10.1056/NEJMoa2002032.

27. Li YC, Bai WZ, Hashikawa T. The neuroinvasive potential of SARS-CoV2 may play a role in the respiratory failure of COVID-19 patients. J Med Virol 2020;92(6):552-555. DOI: 10.1002/jmv.25728.

28. Xiang $\mathrm{P}, \mathrm{Xu} X \mathrm{XM}$, Gao LL, Wang HZ, Xiong HF, Li RH. First case of 2019 novel coronavirus disease with encephalitis. ChinaXiv 2020;202003:00015.

29. Poyiadji N, Shahin G, Noujaim D, Stone M, Patel S, Griffith B. COVID-19associated acute hemorrhagic necrotizing encephalopathy: CT and MRI features. Radiology 2020. 201187. DOI: 10.1148/radiol.2020201187.

30. Zhao H, Shen D, Zhou H, Liu J, Chen S. Guillain-Barré syndrome associated with SARS-CoV-2 infection: causality or coincidence? The Lancet Neurology 2020;19(5):383-384. DOI: 10.1016/S14744422(20)30109-5.

31. Guo YR, Cao QD, Hong ZS, Tan YY, Chen SD, Jin HJ, et al. The origin, transmission and clinical therapies on coronavirus disease 2019 (COVID-19) outbreak-an update on the status. Mil Med Res 2020;7(1):11. DOI: 10.1186/s40779-020-00240-0.

32. Mehta P, McAuley DF, Brown M, Sanchez E, Tattersall RS, Manson JJ. COVID-19: Consider cytokine storm syndromes and immunosuppression. The Lancet 2020;395(10229):1033-1034. DOI: 10.1016/S0140-6736(20)30628-0.

33. Chen C, Zhang XR, Ju ZY, He WF. Advances in the research of cytokine storm mechanism induced by corona virus disease 2019 and the corresponding immunotherapies. Zhonghua Shao Shang Za Zhi. Chin J Bur 2020;36(6):E005. doi: 10.3760/cma.j.cn501120-2020022400088.

34. Wang Y, Wang Y, Chen Y, Qin Q. Unique epidemiological and clinical features of the emerging 2019 novel coronavirus pneumonia (COVID19) implicate special control measures. J Med Virol 2020;92(6): 568-576. DOI: 10.1002/jmv.25748.

35. Li Y, Wang M, Zhou Y, Chang J, Xian Y, Mao L, et al. Acute cerebrovascular disease following COVID-19: a single, retrospective, observational study. Lancet 2020. DOI: 10.2139/ssrn.3550025.

36. Omar S, Clarke R, Abdullah H, Brady C, Corry J, Winter H, et al. Respiratory virus infection up-regulates TRPV1, TRPA1 and ASICS3 receptors on airway cells. PLoS ONE 2017;12(2):e0171681. DOI: 10.1371/ journal.pone.0171681.

37. Giacomelli A, Pezzati L, Conti F, Bernacchia D, Siano M, Oreni L, et al. Self-reported olfactory and taste disorders in patients with severe acute respiratory coronavirus 2 infection: a cross-sectional study. Clin Infect Dis 2020. DOI: 10.1093/cid/ciaa330.

38. Lechien JR, Chiesa-Estomba CM, De Siati DR, Horoi M, Le Bon SD, Rodriguez $A$, et al. Olfactory and gustatory Dysfunctions as a clinical presentation of mild-to-moderate forms of the coronavirus disease (COVID-19): a multicenter european study. Eur Arch Otorhinolaryngol 2020(8):1-1. DOI: 10.1007/s00405-020-05965-1.

39. Han C, Duan C, Zhang S, Spiegel B, Shi H, Wang W, et al. Digestive symptoms in COVID-19 patients with mild disease Severity: Clinical presentation, stool viral RNA testing, and outcomes. Am J Gastroenterol 2020;115(6):916-923. DOI: 10.14309/ ajg.0000000000000664.

40. Pan L, Mu M, Yang P, Sun Y, Wang R, Yan J, et al. Clinical characteristics of COVID-19 patients with digestive symptoms in Hubei, China: a descriptive, cross-sectional, multicenter study. Am J Gastroenterol 2020(5):115. DOI: 10.14309/ajg.0000000000000620.

41. D'Amico F, Baumgart DC, Danese S, Peyrin-Biroulet L. Diarrhea during COVID-19 infection: pathogenesis, epidemiology, prevention and management. Clin Gastroenterol Hepatol 2020;18(8):1663-1672. DOI: https://doi.org/10.1016/j.cgh.2020.04.001. 
42. Zhang C, Shi L, Wang FS. Liver injury in COVID-19: Management and challenges. Lancet Gastroenterol Hepatol 2020;5(5):428-430. DOI: 10.1016/S2468-1253(20)30057-1.

43. Xiao F, Tang M, Zheng X, Liu Y, Li X, Shan H. Evidence for gastrointestinal infection of SARS-CoV-2. Gastroenterol 2020;158(6):1831-1833. DOI: 10.1053/j.gastro.2020.02.055.

44. Wu Y, Guo C, Tang L, Hong Z, Zhou J, Dong X, et al. Prolonged presence of SARS-CoV-2 viral RNA in faecal samples. Lancet Gastroenterol Hepatol 2020;5(5):434-435. DOI: 10.1016/S2468-1253(20)30083-2.

45. Aroniadis OC, DiMaio CJ, Dixon RE, Elmunzer BJ, Kolb JM, Mendelsohn R, et al. Current knowledge and research priorities in the digestive manifestations of COVID-19. Clin Gastroenterol Hepatol 2020;18(8):1682-1684. DOI: 10.1016/j.cgh.2020.04.039.

46. Tian Y, Rong L, Nian W, He Y. Gastrointestinal features in COVID-19 and the possibility of faecal transmission. Aliment Pharmacol Ther 2020;51(9):843-851. DOI: 10.1111/apt.15731.

47. Jin X, Lian JS, Hu JH, Gao J, Zheng L, Zhang YM, et al. Epidemiological, clinical and virological characteristics of 74 cases of coronavirusinfected disease 2019 (COVID-19) with gastrointestinal symptoms. Gut 2020;69(6):1002-1009. DOI: 10.1136/gutjnl-2020-320926.

48. Nobel YR, Phipps M, Zucker J, Lebwohl B, Wang TC, Sobieszczyk ME, et al. Gastrointestinal symptoms and COVID-19: case-control study from the United States. Gastroenterol 2020. S0016-5085(20)30490-X 10.1053/j.gastro.2020.04.017.

49. Wu F, Zhao S, Yu B, Chen YM, Wang W, Song ZG, et al. A new coronavirus associated with human respiratory disease in China. Nat 2020 ;579(7798):265-269. DOI: 10.1038/s4158 6-020-2008-3.

50. Fang D, Ma J, Guan J, Wang M, Song Y, Tian D. Manifestations of digestive system in hospitalized patients with novel coronavirus pneumonia in Wuhan, China: a single-center, descriptive study. Chin J Dig 2020;40(2020-02-23).

51. Yang X, Yu Y, Xu J, Shu H, Liu H, Wu Y, et al. Clinical course and outcomes of critically ill patients with SARS-CoV-2 pneumonia in Wuhan, China: a single-centered, retrospective, observational study. Lancet Respir Med 2020;8(5):475-481. DOI: 10.1016/S22132600(20)30079-5.

52. Li Z, Wu M, Yao J, Guo J, Liao X, Song S, Caution on Kidney Dysfunctions of 2019-nCoV Patients medRxiv; 2020 10.1101/2020.02.;18.

53. Cheng Y, Luo R, Wang K, Zhang M, Wang Z, Dong L, et al. Kidney impairment is associated with in-hospital death of COVID-19 patients. MedRxiv 2020;97(5):829-838. DOI: 10.1016/j.kint.2020. 03.005 .

54. Guan WJ, Liang WH, Zhao Y, Liang HR, Chen ZS, Li YM, et al. Comorbidity and its impact on 1590 patients with COVID-19 in china: a nationwide analysis. Europ Respirat J 2020;55(5):2000547. DOI: 10.1183/13993003.00547-2020.

55. Henry BM, Lippi G. Chronic kidney disease is associated with severe coronavirus disease 2019 (COVID-19) infection. Int Urol Nephrol 2020(6):1-2. DOI: 10.1007/s11255-020-02451-9.

56. Li W, Moore MJ, Vasilieva N, Sui J, Wong SK, Berne MA, et al. Angiotensin-converting enzyme 2 is a functional receptor for the SARS coronavirus. Nat 2003;426(6965):450-454. DOI: 10.1038/ nature0214.

57. Wu P, Duan F, Luo C, Liu Q, Qu X, Liang L, et al. Characteristics of ocular findings of patients with coronavirus disease 2019 (COVID-19) in Hubei Province, China. JAMA Ophthalmol 2020;138(5):575-578. DOI: 10.1001/jamaophthalmol.2020.1291.

58. Cheema M, Aghazadeh $\mathrm{H}$, Nazarali S, Ting A, Hodges J, McFarlane $A$, et al. Keratoconjunctivitis as the initial medical presentation of the novel coronavirus disease 2019 (COVID-19): a case report. Can J Ophthalmol 2020. DOI: 10.1016/j.jcjo.2020.03.003.

59. Seah I, Agrawal R. Can the coronavirus disease 2019 (COVID-19) affect the eyes? A review of coronaviruses and ocular implications in humans and animals. Ocul Immunol Inflamm 2020;28(3):391-395. DOI: 10.1080/09273948.2020.1738501.

60. Connors JM, Levy JH. Thromboinflammation and the hypercoagulability of COVID-19. J Thromb Haemost 2020;18(7): 1559-1561. DOI: 10.1111/jth.14849.
61. Middeldorp S, Coppens M, van Haaps TF, Foppen M, Vlaar AP, Muller $\mathrm{MC}$, et al. Incidence of venous thromboembolism in hospitalized patients with COVID-19. Preprints 2020. 2020040345. DOI: 10.20944/ preprints202004.0345.v1.

62. Klok FA, Kruip MJ, Van der Meer NJ, Arbous MS, Gommers DA, Kant KM, et al. Confirmation of the high cumulative incidence of thrombotic complications in critically ill ICU patients with COVID-19: An updated analysis. Thromb Res 2020;191:148-150. DOI: 10.1016/j. thromres.2020.04.041.

63. Poissy J, Goutay J, Caplan M, Parmentier E, Duburcq T, Lassalle $F$, et al. Pulmonary embolism in COVID-19 patients: awareness of an increased prevalence. Circulation 2020. DOI: 10.1161/ CIRCULATIONAHA.120.047430.

64. Rotzinger DC, Beigelman-Aubry C, von Garnier C, Qanadli SD. Pulmonary embolism in patients with COVID-19: Time to change the paradigm of computed tomography. Thromb Res 2020. DOI: 10.1016/j. thromres.2020.04.011.

65. Simonnet A, Chetboun M, Poissy J, Raverdy V, Noulette J, Duhamel A, et al. Lille intensive care COVID-19 and Obesity study group. High prevalence of Obesity in severe acute respiratory syndrome coronavirus-2 (SARS-CoV-2) requiring invasive mechanical ventilation. Obesity 2020;28(7):1195-1199. DOI: 10.1002/oby.22831.

66. Magro C, Mulvey JJ, Berlin D, Nuovo G, Salvatore S, Harp J, et al. Complement associated microvascular injury and thrombosis in the pathogenesis of severe COVID-19 infection: a report of five cases. Translat Res 2020;220:1-13. DOI: 10.1016/j.trsl.2020.04.007.

67. Lippi G, Plebani M, Henry BM. Thrombocytopenia is associated with severe coronavirus disease 2019 (COVID-19) infections: a metaanalysis. Clinica Chimica Acta 2020;506:145-148. DOI: 10.1016/j. cca.2020.03.022.

68. Uthman IW, Gharavi AE. Viral infections and antiphospholipid antibodies. Semin Arthritis Rheum 2002;31(4):256-263. DOI: 10.1053/ sarh.2002.28303.

69. Zhang Y, Xiao M, Zhang S, Xia P, Cao W, Jiang W, et al. Coagulopathy and antiphospholipid antibodies in patients with Covid-19. N Engl J Med 2020;382(17):e38. DOI: 10.1056/NEJMc2007575.

70. Hall RCW, Hall RCW, Chapman MJ. The 1995 Kikwit Ebola outbreak: lessons hospitals and physicians can apply to future viral epidemics. Gen Hosp Psychiatry 2008;30(5):446-452. DOI: 10.1016/j. genhosppsych.2008.05.003.

71. Naushad VA, Bierens JJ, Nishan KP, Firjeeth CP, Mohammad OH, Maliyakkal AM, et al. A systematic review of the impact of disaster on the mental health of medical responders. Prehosp Disaster Med 2019;34(6):632-643. DOI: 10.1017/S1049023X19004874.

72. Recalcati S. Cutaneous manifestations in COVID-19: a first perspective. J Eur Acad Dermatol Venereol 2020(5). DOI: 10.1111/jdv.16387.

73. Sachdeva M, Gianotti R, Shah M, Lucia B, Tosi D, Veraldi S, et al. Cutaneous manifestations of COVID-19: report of three cases and a review of literature. J Dermatol Sci 2020;98(2):75-81. DOI: 10.1016/j. jdermsci.2020.04.011.

74. Gianotti R. COVID 19 and the skin-heuristic review. Dermo Sprint 2020. In press.

75. Joob B, Wiwanitkit V. Arthralgia as an initial presentation of COVID19: observation. Rheumatol Int 2020(5):1. DOI: 10.1007/s00296-02004561-0.

76. Singhania N, Bansal S, Singhania G. An atypical presentation of novel coronavirus disease 2019 (COVID-19). Am J Med 2020;133(7):e365e366. DOI: 10.1016/j.amjmed.2020.03.026.

77. Casey K, Iteen A, Nicolini R, Auten J. COVID-19 pneumonia with hemoptysis: Acute segmental pulmonary emboli associated with novel coronavirus infection. Am J Emerg Med 2020;38(7):1544. e1-1544.e3. DOI: 10.1016/j.ajem.2020.04.011.

78. Wander P, Epstein M, Bernstein D. COVID-19 presenting as acute hepatitis. Am J Gastroenterol 2020;115(6):941-942. DOI: 10.14309/ ajg.0000000000000660.

79. Weber S, Mayerle J, Irlbeck M, Gerbes AL. Severe liver failure during SARS-CoV-2 infection. Gut 2020;69(7):1365-1367. DOI: 10.1136/gutjnl2020-321350. 